International Review of Research in Open and Distributed Learning Volume 16, Number 3

June -2015

\title{
Learners' Goal Profiles and their Learning Patterns over an Academic Year
}

\author{
Clarence $\mathrm{Ng}$ \\ Australian Catholic University, Australia
}

\begin{abstract}
The present study aimed to examine distance learners' goal profiles and their contrasting patterns of learning and achievements at three different points during an academic year, i.e. in the beginning of the course in relation to learners' general orientations to learning, at the middle of the course in relation to learners' completion of an assignment, and towards the end of the course in relation to learners' preparation for course examination. Two hundred seventy-six adult distance learners completed three survey questionnaires that assessed their motivation and learning at these three learning points. Using person-centred analytical procedures, this study located four groups of learners based on different combinations of mastery and performanceapproach goals. MANOVA results have shown that multiple-goal learners (High mastery/ High performance, $\mathrm{HH}$ ) who held strong mastery and performance-approach goals used more deep and regulatory strategies and showed a higher level of learning interest across three waves of surveys than did those focusing solely on mastery (HL) or performance-approach goals (LH). However, the multiple-goal learners did not have better achievement levels compared to those focusing solely on mastery goals (HL). Given that multiple goal learners learnt with a more engaged pattern, it is less likely that these motivated learners will drop out of distance learning courses and programs. Future studies should explore how these goals can be promoted simultaneously in distance learning.
\end{abstract}

Keywords: Multiple goals; learning; achievement; distance learning; adult learners; prospective design 


\section{Introduction}

The high dropout rate in many distance learning courses and programs (e.g. Simpson, 2013), including the offerings of MOOCs (Liyanagunawardena, Adams, \& Williams, 2013), begs the question of what motivates distance learners to persist with their learning. This question is particularly critical as distance learners often engage in an extended period of learning while juggling commitments derived from personal, familial and employment concerns. Many studies have investigated distance learners' motivation; however, few have taken a longitudinal perspective and utilised established motivational theories to inform their design (Simpson, 2008). This makes it difficult to pinpoint motivational variables that can be manipulated to sustain distance learners' learning motivation. In response, this study used a prospective longitudinal design to examine distance learners' motivation based on achievement goal theory, which is currently a dominant theoretical model guiding the studies on learning motivation (Hulleman, Schrager, Bodmann, \& Harackiewicz, 2010). Achievement goals are students' perceived cognitive purposes that define why and how students engage in learning or achievement behaviours. Different goals are associated with a different pattern of cognition, affect and behaviour (cf. Dweck, 1986; Hulleman et al., 2010). In the literature of distance education, only a limited number of studies has taken an achievement goal perspective (e.g. Ng, 2009), despite its dominance in motivational research and studies in campus-based samples.

The current study aims to examine distance learners' goal profiles and their contrasting patterns of learning and achievement at three different points during an academic year, i.e. in the beginning of the course in relation to learners' general orientations to learning, at the middle of the course in relation to learners' completion of an assignment, and towards the end of the course in relation to learners' preparation for course examination. The results of the current study will significantly contribute to our understanding of distance learners' motivation and add to the nascent literature base of achievement goal research in distance education. In this study, the notion of learning was measured in terms of distance learners' use of learning and regulatory strategies, and their interest and self-efficacy beliefs in learning. The scores distance learners received for their course assignment and examination were taken as measures for achievement levels.

\section{Alternative Achievement Goal Perspectives}

Two types of achievement goals have attracted the most research attention in the past three decades. Mastery goals focus students on the learning task and relate to developing competence, understanding and comprehension. In contrast, performance goals focus students on the self and relate to demonstrating competence and eliciting favourable ability judgments from others (Dweck, 1986; Hulleman et al., 2010; Senko, Hulleman, \& Harackiewicz, 2011). Earlier studies

This work is licensed under a Creative Commons Attribution 4.0 International License. 
have confirmed the differences between these two types of achievement goals. Mastery goals are usually associated with an adaptive learning pattern, characterised by positive cognition, engaging learning behaviours and affect. In contrast, performance goals are often related to a maladaptive pattern, which can be differentiated by a low level of learning engagement and a relatively lower level of performance (e.g. Archer, 1994; Dweck, 1986; Meece \&Holt, 1993).

Based on these early studies, Midgley, Kaplan and Middleton (2001) argued that students should be optimally motivated by mastery goals per se. This particular perspective was labelled as the mastery goal perspective' and was formulated based on the findings derived from early studies on achievement goals unanimously supporting the motivating effects of mastery goals on learning. The mastery goal perspective considers that all forms of performance goals are detrimental to learning and the cost associated with performance demonstration outweighs its benefits. The optimal goal profile should therefore include strong mastery goals but weak performance goals (Meece \& Holt, 1993).

Achievement goal researchers such as Pintrich (2000) and Harackiewicz (Harackiewicz, Barron, Carter, Lehto, \& Elliot, 1997) disputed this mastery goal perspective and advocated a multiple goal perspective based on a trichotomous framework of goals that classifies performance goals into approaching and avoidance orientations. Research shows that maladaptive effects of performance goals were confined to those with an avoidance orientation, such as avoiding looking dumb whilst positive effects were found among performance goals with an approaching orientation like getting a good grade (Elliot \& Harackiewicz, 1996; Skaalvik, 1997). The multiple goal perspective maintains that adopting performance-approach goals simultaneously with mastery goals will enhance the positive effects on learning. In other words, the multiple goal perspective suggests that having strong mastery and performance-approach goals in one's goal profile will be most optimal for learning (e.g. Barron \& Harackiewicz, 2001) and will facilitate achieving different academic outcomes (Harackiewicz et al., 1997).

However, the empirical support for adopting multiple goals over the mastery-only goals is far from conclusive. First, the multiple goal perspective has built on the separation of performance goals into approaching and avoidance orientations. While past research constantly showed that performance-avoidance goals are detrimental to learning, empirical support on the positive effects of performance-approach goals have not been consistent. Second, the current findings on multiple goals cannot firmly establish the relative benefits of holding multiple goals over masteryonly goals (Wolters, 2004). Some studies (e.g. Meece \& Holt, 1993) found that having strong mastery goals and weak performance-approach goals in one's goal profile are the most adaptive form of motivation. Other studies found that students who endorsed both mastery and performance-approach goals as compared to those who endorsed solely mastery goals were not significantly different from each other in certain important aspects including their achievement levels (e.g. Valle et al., 2003). To resolve the conceptual conflict between these two perspectives, Pintrich (2000) argued that there are multiple pathways leading to similar learning outcomes and This work is licensed under a Creative Commons Attribution 4.0 International License 
achievement levels, albeit that students may have differential learning experiences due to the particular goal mix they endorse. Certainly more studies are needed to clarify the effects of multiple goals on learning and achievement despite that increasingly more research evidence (e.g. Darnon, Dompnier, Gilliéron, \& Butera, 2010; Ng, 2009) has affirmed their positive effects on learning. Researching multiple goals using a student group other than Euro-American samples of on-campus students may provide new insights into the operation of multiple goals (Pintrich, Conley, \& Kempler, 2003).

\section{The Current Study}

Adult distance learners are a unique student group who differ from campus-based students in important ways. This student group is often populated by mature learners who often have multiple roles derived from familial and employment responsibilities (Eppler \& Harju, 1997; Sachs, 2001). As a result, learning in a part-time mode and using a prolonged study period to complete a degree programme are common characteristics among distance learners. This, of course, calls into question distance learners' sustained motivation; what motivates distance learners to engage in such a prolonged process of learning? In the distance learning literature, distance learners are generally described as learning-oriented. To learn for knowledge and personal development are often distance learners' main motivational foci when embarking on distance learning (Eppler \& Harju, 1997; Ng, 2006). In addition, Eppler and Harju (1997) specifically found that adult learners, compared to young students, endorsed the use of mastery goals over performance goals. Sachs (2001) found that mastery goals predicted adult learners' enjoyment in completing course assignments but not their graded performance. More direct support regarding the significant role of mastery goals for distance learners can be derived from several recent studies (Ng, 2006, 2008, 2009; Remedios \& Richardson, 2012) that produced repeated empirical evidence supporting that learning for knowledge improvement, understanding and competence development have been dominant forms of motivation for this group of learners.

However, the extent to which mastery goals are the sole motivational source for distance learners is questionable. Distance learners often have other learning goals that focus on career advancement and different social considerations (e.g. Cochrane, 2000; Dearnley \& Matthew, 2000; Cannon, Umble, Steckler, \& Shay, 2001; Lyall \& McNamara, 2000; Miller \& Smith, 1998; von Prummer, 1990; Wilson \& Bagley, 1999). Adopting a multiple goal perspective, Ng (2008) argued that different goals would provide different forms of motivational support that help distance learners maintain their focus and cope with the demands of prolonged period of learning while juggling work and family commitments simultaneously (cf. Barron \& Harackiewicz, 2001). In this specific study ( $\mathrm{Ng}, 2008)$, it was found that distance learners who endorsed strong performance-approach goals alongside other goals had a better achievement level than did those 
focusing solely on mastery goals. In another study investigating the process of completing a compulsory course assignment, $\mathrm{Ng}$ (2009) found that distance learners who held strong performance-approach goals in their profiles had better achievement results compared to those focusing on work avoidance goals. In addition, distance learners who endorsed both mastery and performance-approach goals had the most adaptive pattern of engagement during the process of completing the assignments. This adaptive engagement pattern was measured in terms of strategy use, valuing of the task, self-efficacy, levels of anxiety and mastery focused responses to feedback on their work. In a more recent study, Remedios and Richardson (2012) found that British distance learners' performance-approach goals predicted their course work and examination marks. While accumulated evidence is supportive of the importance of performance-approach goals to adult learners, some studies found contradictory evidence discrediting this (e.g. Eppler \& Harju, 1997). Sachs (2001) even argued that performance goals are not relevant to adult learners because they have already demonstrated their academic abilities through their degree qualifications. More research is warranted to examine the combined effects of performanceapproach goals and mastery goals on learning and achievement among adult distance learners.

Taken together, this study argues that both mastery and performance-approach goals are important motivational goals in the distance learning process and that they can contribute in different ways to sustain an adaptive pattern of engagement for distance learners (cf. Barron \& Harackiewicz, 2001). Endorsing these two types of goals simultaneously allows distance learners to vary their motivational focus on competence development or competence demonstration in response to the specific demands of different learning situations. Most of the previous studies (e.g. Ng, 2008, 2009), however, were limited by a cross-section design and failed to show the effects of endorsing simultaneously mastery goals and performance-approach goals over time. More significantly, there is a lack of research that looks into distance learners' motivation from a longitudinally perspective covering learning at different points over an academic year. Addressing this gap, the current study conducted three waves of surveys within an academic year to assess distance learners' motivated learning process in relation to 1) their general orientation to learning at the beginning of the academic year (Time 1); 2) the completion of an assignment five months later (Time 2); and 3) examination preparation at the end of the academic year (Time 3).

The key research question is whether multiple-goal learners will hold a more engaged learning pattern and have better achievement levels over the academic year when compared to other types of goal users. To examine the effects of multiple goals at the individual level, four groups of learners were examined: high-mastery/ high-performance learners $(\mathrm{HH})$, high-mastery/lowperformance learners (HL), low-mastery/ high-performance learners (LH), and low-mastery/lowperformance learners (LL). The main issue was whether group membership moderated distance learners' engagement patterns in three data collection points. Engagement patterns were measured by a host of dependent variables including learning strategies, regulatory strategies, learning interest, self-efficacy and achievement levels. Based on the multiple goal perspective, this study hypothesised that the multiple-goal group $(\mathrm{HH})$ would have a more engaged learning 
pattern in Time 1, 2 and 3. In particular, compared to the other three groups, the HH group would hold higher levels of interest and self-efficacy, use more deep and regulatory strategies but less surface strategies during Time 1, 2 and 3. In terms of achievement levels, it was assumed that the HH group would have higher levels of achievement in both Time 2 and 3 (cf. Ng, 2008, 2009; Valle et al., 2003).

\section{Method}

\section{Participants}

The participants were 272 adult learners enrolled in different degree programmes offered by the four faculties (Education 43.5\%, Science 9.4\%, Arts 40.2\%, and Business 6.9\%) of a distance learning university in Hong Kong. The majority of these participants were adult learners within the age spans of 21-30 (30.8\%), 31-40 (42\%), and 41-50 (20.7\%). The sample was gender biased with $75 \%$ females and $19.5 \%$ males.

\section{Procedure}

A random sample of distance learners was generated from the university's enrolment system, and from which 400 potential participants were selected from major degree programmes offered by the university's four academic faculties in the beginning of an academic year. All the selected learners had enrolled in a 10 credit-point year-long course that required learners to complete four written assignments and an end-of-year examination. An invitation letter explaining the design of the research was sent to these potential participants. In response, 308 distance learners agreed to participate.

The data were collected at the beginning of the academic year (Time 1), in the middle of the academic year after the learners had completed their second written assignment (Time 2), and finally, at the end of the academic year before the examination period (Time 3). In each round of data collection, the participants were sent a cover letter together with a questionnaire and an enclosed returning envelope. Follow-up strategies including sending a reminder letter and contacting participants by phone were adopted to encourage them to complete and return the questionnaires. Thirty-two learners failed to return at least one of the questionnaires and were excluded from the study. The final sample was made up of 272 learners (a response rate of 88.31\%) who had completed three questionnaires as required.

\section{Measures}

The questionnaires of Time 1, 2 and 3 assessed learners' achievement goals, use of strategies, selfefficacy and learning interest in relation to their general learning orientation at the course level (Time 1), the completion process of an academic essay (Time 2) and the preparation for final 
examination (Time 3). All the items in Time 1 survey were preceded by a stem "While studying this course ...". Time 2 survey items were preceded by a stem, "When completing this essay..." and were worded in such a way that learners were required to focus on how they had completed the second written assignment. In Time 3, all the items were preceded by a stem, "While preparing for the exam...". Items in Time 1 and 3 were set in a 5-point Likert scale (1=strongly disagree to 5 = strongly agree) while those in Time 2 followed a 7-point Likert-scale ( $1=$ strongly disagree to 7 = strongly agree) in $\mathrm{Ng}$ (2009). Table 1 shows the Alpha values for each construct in three waves of surveys.

\section{Achievement goals.}

The measures of achievement goals for Time 1 and 3 were adapted from the Patterns of Adaptive Learning Survey (PALS, Midgley et al., 2000). In the Time 2 survey, items were adapted from a previous study on distance learners' completion of course assignments ( $\mathrm{Ng}, 2009)$. Two scales of achievement goals were included in all three surveys: mastery goals and performance-approach goals. The mastery goals scale assessed a personal focus on learning and competence development in the learning of the course, completion of an assignment and preparation for examination. Five items were included in Time 1. A sample item in the Time 1 survey was "While studying this course, I want to learn something new". Seven items assessed learners' mastery goals for completing an academic assignment. A sample item was "When completing this essay, I hoped to deepen my understanding of this course even though I might not get a high mark". Five items assessed learners' mastery goals for examination preparation. A sample item was "While preparing for the exam, I want to learn as much as possible in my revision".

Performance-approach goals assessed learners' personal focus on gaining high achievement and demonstrating competence. Five items were included in Time 1. A sample item in the Time 1 survey was "While studying this course, I want to get a good result". Four items assessed distance learners' performance-approach goals for completing an assignment in Time 2. A sample item was "While completing this essay, I intended to get a high mark". In Time 3, five items were included in the scale of performance-approach goals for examination preparation but one of them was dropped in order to improve the reliability score for this construct. Four items made up the performance-approach goal construct in Time 3. A sample item was "While preparing for the exam, I want to get a high mark". The original questionnaire in Time 1, 2 and 3 also included items assessing performance-avoidance goals, which were not included in the subsequent analyses due to low reliability.

\section{Learning strategies.}

Learning strategies in the Time 1, 2 and 3 surveys included two contrasting scales: surface and deep strategies. Surface strategies assessed learners' use of rehearsal-based strategies such as rote learning and memorisation that lead to superficial understanding. In contrast, the deep strategies construct included strategies that promote deep learning and encourage effort expenditure. Items 
assessing these two contrasting types of strategies in Time 1 and 3 were adapted from the Learning Approach Questionnaire (Biggs, 1987) while Time 2 items were taken from Ng (2009). Each surface and deep strategy scale in Time 1, 2, and 3 included five items. The sample items of surface strategies in the Time 1, 2 and 3 respectively were, "I learn the course materials mainly by rote, going over and over them until I know them by heart" (Time 1), "I just studied those materials specified in the essay guidelines and thought it was unnecessary to study extra materials" (Time 2), and "I go over and over the course materials to memorise the important content that is likely to appear in the exam" (Time 3). The sample items for assessing deep strategies in Time 1, 2, and 3 respectively were, "I think of real-life situations in which the materials that I am learning would be useful" (Time 1), "I studied relevant materials related to this essay and made notes carefully" (Time 2), and "I try to relate different parts of the course in my revision" (Time 3).

\section{Regulatory strategies.}

Regulatory strategies measured learners' self-monitoring of their learning. Five items adapted from the Motivated Strategies for Learning Questionnaire (MSLQ, Pintrich, Smith, \& Garcia, 1993) assessed this construct in Time 1 and 3. Sample items in the Time 1 and 3 respectively were, "I ask myself questions to help focus my understanding" (Time 1) and "I noticed that I often missed important points and needed to study them again" (Time 3). Five items taken from Ng (2009) were included in the construct of regulatory strategies for completing an assignment. A sample item was "I have changed my usual way of study in order to understand the difficult materials central to this essay".

\section{Efficacy beliefs.}

The efficacy beliefs scale used three items adapted from MSLQ (Pintrich et al., 1993) to assess learners' perceptions of their abilities to complete the course and assignment, and prepare for the examination. The sample items for Time 1, 2 and 3 respectively were, "I'm certain I can understand the most difficult concepts and theories presented in the Course" (Time 1), "I believe I am able to do well in this essay" (Time 2), and "I am confident that I am able to do well in the exam" (Time 3).

\section{Interest.}

Distance learners' learning interest was assessed using 3 items adapted from MSLQ in Time 1, 2 and 3 (Pintrich et al., 1993). The sample items for Time 1, 2 and 3 respectively were, "I found this course very interesting and enjoyed the time spent on it" (Time 1), "I enjoyed doing this assignment" (Time 2), and "I enjoyed doing the revision for the exam" (Time 3). 


\section{Outcome variables.}

Two achievement variables assessed the learning outcomes. Distance learners' scores of their second assignment and examination results were collected from course convenors with the permission from the participants.

\section{Results}

Table 1 shows the means, standard deviations and reliability scores for the variables in Time 1, 2 and 3. Table 2 shows the results of correlation analyses. As can be seen, distance learners' mastery goals were related positively to self-efficacy, learning interest, and the use of deep and regulatory strategies across Time 1, 2 and 3. These adaptive goals were negatively related to the use of surface strategies across the three data collection points. These relational patterns were consistent with those found among campus-based students (e.g. Barron \& Harackiewicz, 2001). Performance-approach goals appeared to be adaptive in this study. These goals for performance demonstration were related positively to self-efficacy, learning interest, and the use of deep and regulatory strategies across Time 1, 2 and 3 but a negative relationship was found between these goals and surface strategies. Both mastery and performance-approach goals were not related to distance learners' assignment scores (Time 2) and examination results (Time 3).

Table 1

Descriptive Statistics

\begin{tabular}{|c|c|c|c|c|c|c|c|c|c|}
\hline & \multicolumn{3}{|c|}{ Time 1 (Likert scale 1-5) } & \multicolumn{3}{|c|}{ Time 2 (Likert scale 1-7) } & \multicolumn{3}{|c|}{ Time 3 (Likert scale 1-5) } \\
\hline & Mean & $\mathrm{SD}$ & Alpha & Mean & $\mathrm{SD}$ & Alpha & Mean & $\mathrm{SD}$ & Alpha \\
\hline Mastery goals & 3.78 & .53 & .72 & 5.23 & .81 & .86 & 3.72 & .53 & .73 \\
\hline $\begin{array}{l}\text { Performance- } \\
\text { approach goals }\end{array}$ & 3.50 & .68 & .63 & 4.95 & .74 & .64 & 3.38 & .65 & .66 \\
\hline $\begin{array}{l}\text { Surface } \\
\text { strategies }\end{array}$ & 2.82 & .73 & .63 & 3.75 & .99 & .69 & 2.84 & .54 & .54 \\
\hline Deep strategies & 3.18 & .54 & .73 & 4.98 & .84 & .80 & 3.22 & .54 & .75 \\
\hline $\begin{array}{l}\text { Regulatory } \\
\text { strategies }\end{array}$ & 3.19 & .46 & .72 & 4.43 & 1.03 & .63 & 3.16 & .49 & .79 \\
\hline Efficacy belief & 3.07 & .63 & .78 & 4.57 & .81 & .70 & 3.09 & .61 & .76 \\
\hline $\begin{array}{l}\text { Learning } \\
\text { interest }\end{array}$ & 3.55 & .67 & .84 & 5.02 & .92 & .78 & 3.63 & .70 & .83 \\
\hline
\end{tabular}

This work is licensed under a Creative Commons Attribution 4.0 International License. 
Table 2

Correlation Analyses

\begin{tabular}{|c|c|c|c|c|c|c|c|c|c|c|c|c|c|c|c|c|c|c|c|}
\hline & 1 & 2 & 3 & 4 & 5 & 6 & 7 & 8 & 9 & 10 & 11 & 12 & 13 & 14 & 15 & 16 & 17 & 18 & 19 \\
\hline 1. T1 Mastery goals & -- & & & & & & & & & & & & & & & & & & \\
\hline $\begin{array}{l}\text { 2. T1 Performance- } \\
\text { approach goals }\end{array}$ & .18 & -- & & & & & & & & & & & & & & & & & \\
\hline 3. T1 Surface strategies & -.19 & -.12 & -- & & & & & & & & & & & & & & & & \\
\hline 4. T1 Deep strategies & .45 & .21 & -.32 & -- & & & & & & & & & & & & & & & \\
\hline $\begin{array}{l}\text { 5. T1 Regulatory } \\
\text { strategies }\end{array}$ & .30 & .24 & -.24 & .67 & -- & & & & & & & & & & & & & & \\
\hline 6. T1 Efficacy & .31 & .41 & -.24 & .37 & .40 & -- & & & & & & & & & & & & & \\
\hline 7. T1 Interest & .58 & .13 & -.30 & .46 & .34 & .48 & -- & & & & & & & & & & & & \\
\hline 8. T2 Surface strategies & & & .21 & & -.14 & -.15 & -.15 & -- & & & & & & & & & & & \\
\hline 9. T2 Deep strategies & .23 & .26 & & .42 & .46 & .21 & 18 & & -- & & & & & & & & & & \\
\hline $\begin{array}{l}\text { 10. T2 Regulatory } \\
\text { strategies }\end{array}$ & & .19 & & .21 & .24 & & & .35 & .48 & -- & & & & & & & & & \\
\hline 11. T2 Efficacy & .18 & .15 & .15 & .30 & .32 & .36 & .24 & -.38 & .28 & & -- & & & & & & & & \\
\hline 12. T2 Interest & .37 & .17 & & .38 & .24 & .17 & .42 & -.19 & .33 & .13 & .48 & -- & & & & & & & \\
\hline $\begin{array}{l}\text { 13. T3 Surface } \\
\text { strategies }\end{array}$ & -.20 & & .52 & .29 & -.25 & -.19 & -.32 & .28 & & .13 & -.17 & -.22 & -- & & & & & & \\
\hline 14. T3 Deep strategies & .39 & .20 & -.34 & .65 & .48 & .34 & .46 & -.13 & .45 & .24 & .36 & .41 & -.30 & -- & & & & & \\
\hline $\begin{array}{l}\text { 15. T3 Regulatory } \\
\text { strategies }\end{array}$ & .23 & .24 & -.32 & .57 & .62 & 30 & 27 & -.13 & .50 & .27 & .29 & .25 & -.24 & .65 & -- & & & & \\
\hline 16. T3 Efficacy & 19 & .26 & -.19 & .38 & .40 & .53 & .31 & -.35 & .27 & & .49 & .27 & .25 & .46 & .43 & -- & & & \\
\hline 17. T3 Interest & .47 & & -.30 & .39 & .30 & .30 & .65 & -.25 & .24 & & .37 & .49 & -.37 & .54 & .35 & .50 & -- & & \\
\hline $\begin{array}{l}\text { 18. T2 Assignment } \\
\text { score }\end{array}$ & -.14 & & & & & & & -.30 & & -.20 & .31 & & & & & .20 & .13 & -- & \\
\hline 19. T3 Exam score & -.14 & & & & -.12 & & & -.23 & & -.21 & & & & & & & & .29 & -- \\
\hline
\end{tabular}

Note 1: $*$ p $<05 ; * * p<01$ (only significant correlation coefficients were shown) 


\section{Person-Centred Analyses}

Following Pintrich (2000), this study used the median split technique to classify learners into different groups of goal users. To address the concern that median split may impose an artificial structure without considering the underlying structure of the data, the current study used cluster analysis and discriminant function analyses to verify the membership of the learner groups produced by the median split technique.

Using the median scores (3.80 for mastery goal and 3.33 for performance-approach goals in Time 1), four groups of distance learners were produced: high mastery / high performance learners ( $\mathrm{HH} ; \mathrm{N}=65)$, high mastery / low performance learners (HL; $\mathrm{N}=53$ ), low mastery / high performance learners ( $\mathrm{LH} ; \mathrm{N}=68$ ), and low mastery / low performance learners ( $\mathrm{LL} ; \mathrm{N}=86$ ). A non-hierarchical cluster analysis specifying a 4-cluster solution was conducted to compare the learners' membership in different goal-user groups derived from both classifying techniques. The resulting cluster solution located four clusters of learners with similar goal properties to the groups derived from the median split technique. Comparing the membership of corresponding groups produced by these two classification methods, $97.43 \%$ of learners were classified into identical groups using both methods. Only seven learners had been classified differently. Further, a discriminant function analysis significantly predicted the membership in these four groups derived from the median split technique using mastery and performance-approach goals as predictors. According to this significant discriminant function, $96.7 \%$ were classified correctly into $\mathrm{HH}, \mathrm{HL}, \mathrm{LH}$ and LL groups. It can be concluded that the groupings of learners produced by the median split technique were valid.

To check the stability of these groupings of learners over time, the median split procedures were repeated based on learners' scores on achievement goals in Time 2 and 3, respectively. The membership in corresponding groups was then compared across three waves. It was found that the classification of learners based on Time 2 and 3 data was $98 \%$ and 99\% identical with the Time 1 grouping described above. It can then be concluded that the groupings based on Time 1 data were stable over the whole academic year.

These four groups did not differ in gender composition. However, a significant Chi square test $\left(\chi^{2}=30.86\right.$, d.f. $\left.=6, p<0001\right)$ found that $\mathrm{HH}$ and HL groups were populated by older learners while LH and LL groups had more younger adults. The age factor was taken as a covariate in the subsequent analyses. Mixed ANOVAs were conducted using strategies, self-efficacy and interest as within factors, groups as between-group factor, and the age factor was entered as a covariate. Standardised scores were used in these analyses. The main effects (time and group) and two-way interactions were examined. Table 3 shows the descriptive statistics for these four goal user groups in Time 1, 2 and 3.

This work is licensed under a Creative Commons Attribution 4.0 International License. 
Table 3

Means and Standard Deviations for Strategies, Efficacy, Interest, Goals and Achievement Levels by Four Goal Groups

\begin{tabular}{|c|c|c|c|c|c|c|c|c|}
\hline \multirow[b]{2}{*}{$\begin{array}{l}\text { Dependent } \\
\text { variables }\end{array}$} & \multicolumn{2}{|c|}{$\begin{array}{l}\text { High- } \\
\text { mastery/ High } \\
\text { performance } \\
(\mathrm{n}=65)\end{array}$} & \multicolumn{2}{|c|}{$\begin{array}{l}\text { High mastery / } \\
\text { low performance } \\
(n=53)\end{array}$} & \multicolumn{2}{|c|}{$\begin{array}{l}\text { Low mastery / } \\
\text { High performance } \\
(\mathrm{n}=68)\end{array}$} & \multicolumn{2}{|c|}{$\begin{array}{l}\text { Low mastery / } \\
\text { low performance } \\
(\mathrm{n}=86)\end{array}$} \\
\hline & $\mathrm{M}$ & SD & $\mathrm{M}$ & SD & $\mathrm{M}$ & $\mathrm{SD}$ & $\mathrm{M}$ & $\mathrm{SD}$ \\
\hline $\begin{array}{l}\text { Surface } \\
\text { strategies-T1 }\end{array}$ & 2.69 a & .71 & $2.68^{a}$ & .63 & $2.87 \mathrm{a}$ & .78 & $2.93^{a}$ & .74 \\
\hline $\begin{array}{l}\text { Surface } \\
\text { strategies-T2 }\end{array}$ & $3.47^{a}$ & .89 & $3.49^{a}$ & 1.11 & $3.56^{\mathrm{a}}$ & 1.02 & $3.61^{\mathrm{a}}$ & .92 \\
\hline $\begin{array}{l}\text { Surface } \\
\text { strategies-T3 }\end{array}$ & $2.73 a, b$ & .53 & $2.67^{b}$ & .56 & $2.89 \mathrm{a}, \mathrm{b}$ & .56 & $2.98^{\mathrm{a}}$ & .52 \\
\hline $\begin{array}{l}\text { Deep } \\
\text { strategies-T1 }\end{array}$ & $3.52^{\mathrm{a}}$ & .52 & $3.37^{b}$ & .46 & $3.05^{c}$ & .58 & $2.98^{c}$ & .39 \\
\hline $\begin{array}{l}\text { Deep } \\
\text { strategies-T2 }\end{array}$ & $5.42^{\mathrm{a}}$ & .79 & $4.94^{b}$ & .79 & $4.89^{c}$ & .98 & $4.78^{c}$ & .67 \\
\hline $\begin{array}{l}\text { Deep } \\
\text { strategies-T3 }\end{array}$ & $3.53^{a}$ & .51 & $3.35^{b}$ & .56 & $3.07 \mathrm{c}$ & .50 & $3.06^{c}$ & .43 \\
\hline $\begin{array}{l}\text { Regulatory } \\
\text { strategies-T1 }\end{array}$ & $3.43^{a}$ & .48 & $3.22^{b}$ & .44 & $3.16^{b}$ & .50 & $3.04^{\mathrm{b}}$ & .36 \\
\hline $\begin{array}{l}\text { Regulatory } \\
\text { strategies-T2 }\end{array}$ & $4.81^{a}$ & 1.04 & $4.30^{b}$ & 1.06 & $4.49 \mathrm{~b}$ & .95 & $4.29 \mathrm{~b}$ & .92 \\
\hline $\begin{array}{l}\text { Regulatory } \\
\text { strategies-T3 }\end{array}$ & $3.40^{\mathrm{a}}$ & .41 & $3.24^{b}$ & .47 & $3.10^{b}$ & .52 & $3.07^{b}$ & .31 \\
\hline $\begin{array}{l}\text { Efficacy } \\
\text { beliefs-T1 }\end{array}$ & $3.51^{\mathrm{a}}$ & .62 & $3.00^{b}$ & .55 & $3.10^{b}$ & .56 & $2.81^{b}$ & .50 \\
\hline $\begin{array}{l}\text { Efficacy } \\
\text { beliefs-T2 }\end{array}$ & $4.75^{a}$ & .71 & $4.61^{b}$ & .91 & $4.58^{b}$ & .85 & $4.45^{b}$ & .68 \\
\hline $\begin{array}{l}\text { Efficacy } \\
\text { beliefs-T3 }\end{array}$ & $3.36^{a}$ & .52 & $3.09 \mathrm{~b}$ & .61 & $3.13^{b}$ & .59 & $2.98^{b}$ & .49 \\
\hline Interest-T1 & $3.95^{a}$ & .53 & $3.84^{\mathrm{a}}$ & .54 & $3.34^{b}$ & .61 & $3.30^{b}$ & .59 \\
\hline Interest-T2 & $5.16^{\mathrm{a}}$ & .96 & $5.07^{a}$ & .75 & $4.78^{a}$ & .98 & $4.52^{b}$ & .90 \\
\hline Interest-T3 & $3.91^{\mathrm{a}}$ & .56 & $3.94^{\mathrm{a}}$ & .63 & $3.44^{b}$ & .72 & $3.51^{\mathrm{b}}$ & .43 \\
\hline $\begin{array}{l}\text { Assignment } \\
\text { score } \\
(0-100)\end{array}$ & $72.27^{a}$ & 14.00 & $72.72^{\mathrm{a}}$ & 13.24 & 73.58 a & 11.55 & $73.53^{a}$ & 11.98 \\
\hline $\begin{array}{l}\text { Examination } \\
\text { score } \\
(0-100)\end{array}$ & $59.78^{a}$ & 12.27 & $59.74^{\mathrm{a}}$ & 11.79 & $62.92^{\mathrm{a}}$ & 10.09 & $63.50^{a}$ & 12.10 \\
\hline
\end{tabular}

Note 1. T1=Time 1; T2=Time 2; T3=Time 3; Note 2. T1 \& T3 scores ranged between 1 and 5; T2 scores ranged between 1 and 7; Note 3 . Means within a row with different superscripts are significantly different from one another; Note 4. Standardised scores were used in mixed ANOVA analyses. 


\section{Surface strategies.}

The four groups differed in the use of surface strategies, $F_{(1,245)}=2.65, p<.05, \eta^{2}=.03$. In particular, the group differences were found in Time 3 where the LL group had the highest scores in surface strategies and HL had the lowest scores; the HH and LH groups were not different from each other in the use of surface strategies. However, both time and time x group interactive effects were not significant.

\section{Deep strategies.}

The four groups differed in the use of deep strategies, $F_{(1,245)}=15.94, p<0001, \eta^{2}=.16$. The HH group had the highest scores in the use of deep strategies followed by the HL group across three surveys. Both LH and LL groups had a similar low level in the use of deep strategies. However, this significant group effect was qualified by a significant time $\mathrm{x}$ group interaction, Huynh-Feldt $F_{(5.85,489.63)}=2.61, p<.05, \eta^{2}=.03$, indicating that the inter-group difference in the use of deep strategies was a function of Time. As shown in Figure 1, the HH and HL groups had higher levels of deep strategies than did LH and LL groups in Time 1. An identical pattern was found again by the end of the year. When completing the assignment, the HH group had the highest level of deep strategies. The HL group, however, experienced a significant drop in the use of deep strategies when completing the assignment in Time 2 .

This work is licensed under a Creative Commons Attribution 4.0 International License. 


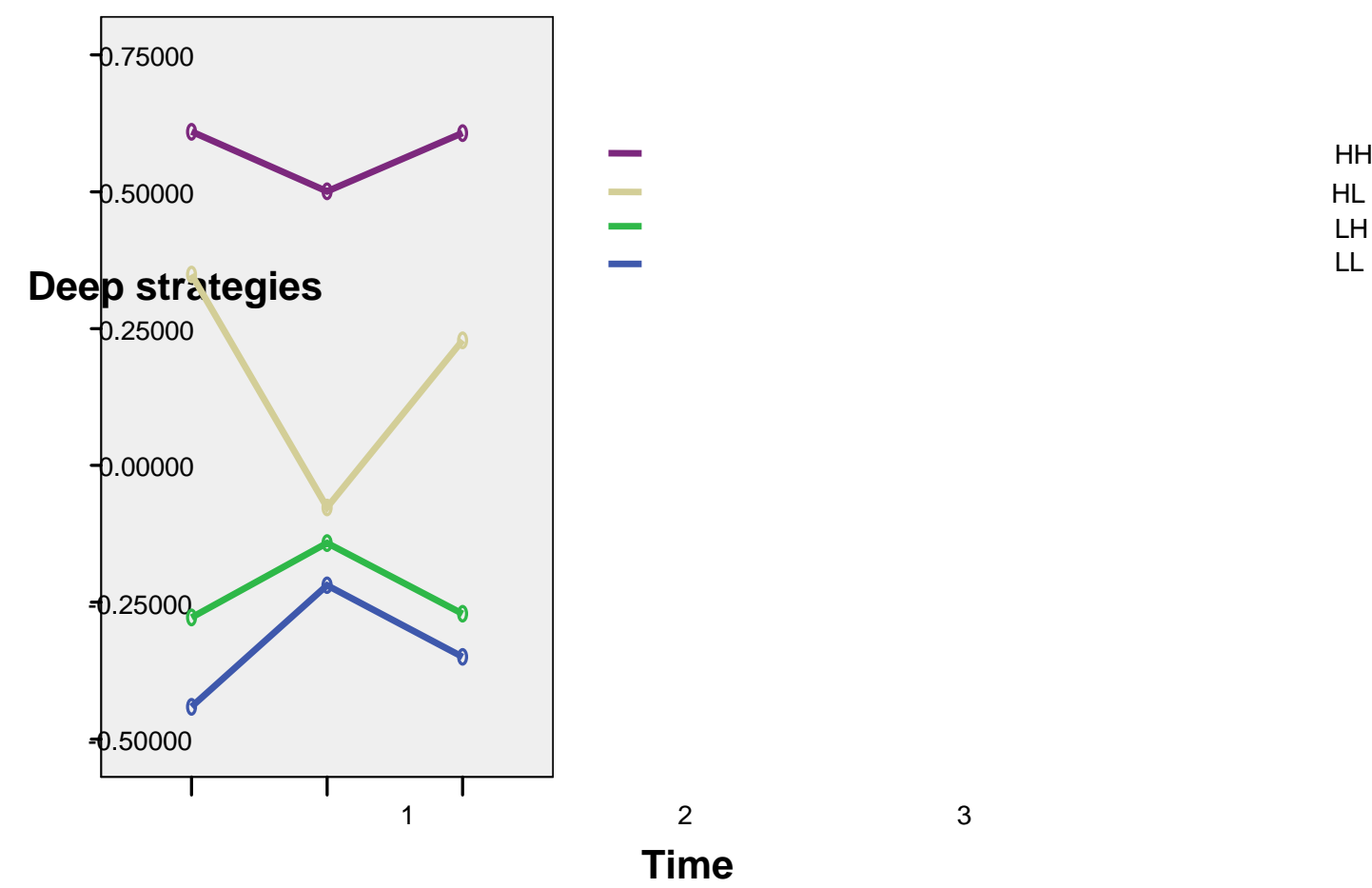

Figure 1. Time x Group Interaction: Deep strategies.

Note: HH=High Mastery, High Performance; HL=High Mastery, Low Performance; LH=Low Mastery, High Performance; LL=Low Mastery, Low Performance; Time1=At the beginning of the academic year; Time 2=After completing the second written assignment; Time 3=During the preparation for the final examination

\section{Regulatory strategies.}

The four groups differed with each other in the use of regulatory strategies, $F_{(1,245)}=9.89$, $\mathrm{p}<.0001, \eta^{2}=.11$. The HH group used more regulatory strategies than did the other three groups in Time 1, 2, and 3. The main effect on time and time x group interactive effect were nonsignificant. 


\section{Self-efficacy.}

A significant main effect on group, $F_{(1,245)}=11.01, p<.0001, \eta^{2}=.12$, indicates that these four groups of learners differed in their levels of efficacy beliefs. HH and HL groups had a stronger sense of self-efficacy than did the LH and LL groups. A significant time $\mathrm{x}$ group effect indicates that such a differential pattern varied with time, Huynh-Feldt $F_{(5.99,509.04)}=3.31, p<.005, \eta^{2}=.04$. As shown in Figure 2, the $\mathrm{HH}$ group had higher levels of efficacy beliefs than did the other three groups in Time 1, 2 and 3.

\section{Interest.}

A significant main effect, $\mathrm{F}_{(1,245)}=21.07, \mathrm{p}<.0001, \eta^{2}=.21$, indicates that the four groups differed in their levels of learning interest. A significant time $\mathrm{x}$ group interaction qualified this group differential pattern, Huynh-Feldt $\mathrm{F}_{(5.72,471.23)=2.17} \mathrm{p}<.05, \eta^{2}=.03$. Figure 3 shows that both $\mathrm{HH}$ and HL groups had higher interest levels than did LH and LL groups in Time 1 and 3. In Time 2, the LH group had greater interest in completing the assignment. The HH, HL, and LH groups had similar levels of interest.

\section{Achievement scores.}

The four groups did not differ from one another on achievement scores. In other words, they had similar scores in their assignments in Time 2 and examination in Time 3. This intriguing result will be discussed in the next section. 


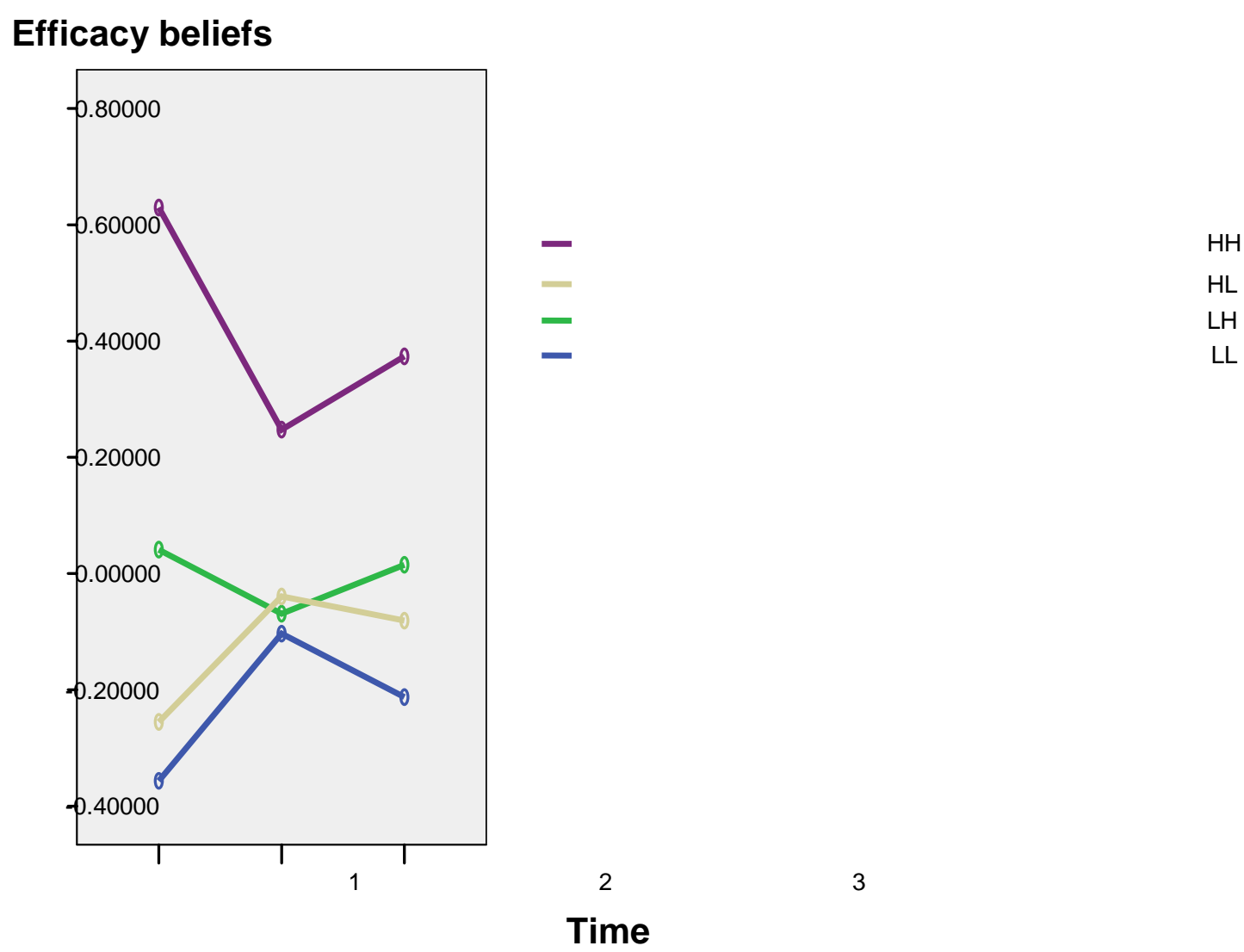

Figure 2. Time x group interaction: Efficacy beliefs

Note: HH=High Mastery, High Performance; HL=High Mastery, Low Performance; LH=Low Mastery, High Performance; LL=Low Mastery, Low Performance; Time1=At the beginning of the academic year; Time 2=After completing the second written assignment; Time 3=During the preparation for the final examination. 


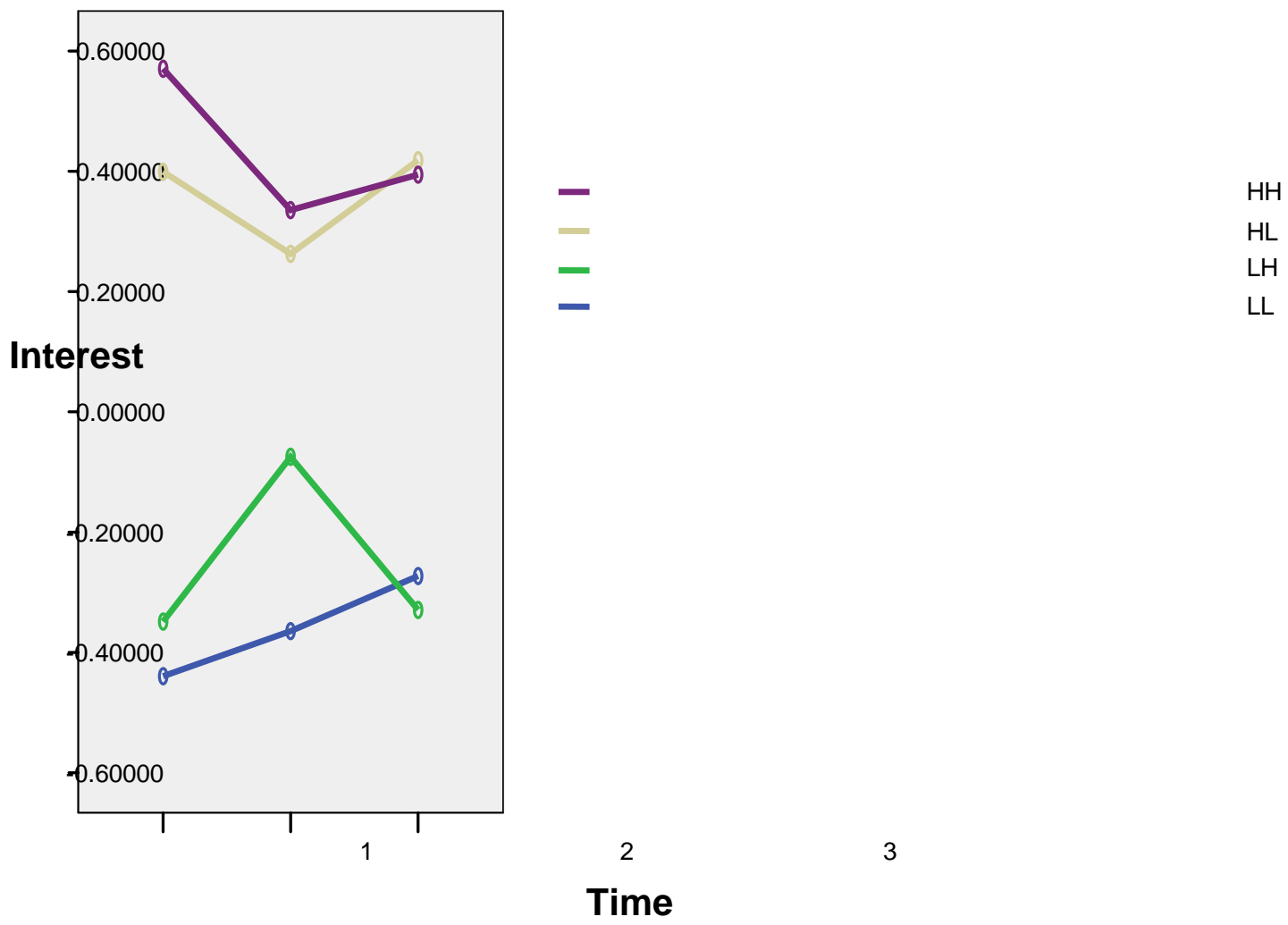

Figure 3. Time x group interaction: Interest.

Note: HH=High Mastery, High Performance; HL=High Mastery, Low Performance; LH=Low Mastery, High Performance; LL=Low Mastery, Low Performance; Time1=At the beginning of the academic year; Time 2=After completing the second written assignment; Time 3=During the preparation for the final examination. 


\section{Discussion}

The research question in this study focused on the differential patterns of learning and achievement associated with distance learners holding different types of goals at three different points of learning during an academic year. A key comparison can be made between distance learners who were high in both mastery and performance-approach goals $(\mathrm{HH})$ and those high in mastery goals but low in performance-approach goals (HL). According to the multiple goal perspective, the $\mathrm{HH}$ group should show a more adaptive pattern in the use of strategies, levels of efficacy and learning interest in Time 1, 2 and 3. Aligning with previous studies ( $\mathrm{Ng}, 2008,2009)$, the current results favoured the HH group over the HL group. While the two groups showed similar levels in their interest in learning and endorsed a similar level of deep strategies at the beginning and end of the academic year, the $\mathrm{HH}$ learners were more efficacious and used more regulatory strategies. Unlike the HL group, HH learners did not show a significant decline in the use of deep strategies when completing their assignments in Time 2. Overall these findings were in line with previous research, such as Valle et al. (2003), that supports the benefits of endorsing multiple goals at the individual level.

In terms of achievement levels, the median split analyses failed to find any significant result supporting the claim that endorsing multiple goals would be associated with a higher level of achievement. Contrary to the prediction, the HH group did not have better scores in their assignments and examination results. Though the four groups did not differ in their achievement scores, the mean scores for the HH group were unexpectedly the lowest among the four groups. This intriguing finding was inconsistent with previous studies using similar student groups $(\mathrm{Ng}$, 2008, 2009). More research is needed to examine the relationship between achievement and goals. The inconsistency result calls into question the benefits of holding multiple goals and whether distance educators should promote them if they will not necessarily lead to higher achievement. In the discussion below, the concept of 'multiple pathways' (Pintrich, 2000) was used to interpret the nonsignificant relationship between achievement levels and different goal profiles.

Following Pintrich (2000), it can be argued that different distance learner groups learnt through different pathways but arrived at a similar level of achievement. The HH group showed a highly engaged pattern characterised by strong regulation, deep learning, and high levels of interest and confidence. The HL group had a similar learning trajectory over the year except that they used less deep and regulatory strategies and had a lower level of interest. In contrast, the LH and LL groups showed a rather disengaged pattern of learning over the academic year characterised by surface learning and low levels of regulation, interest and confidence. This multiple pathway argument alerts distance educators to different patterns of learning associated with different goal profiles. The important question is which goal profile is associated with a more engaged pattern that is likely to sustain distance learners' motivation to learn. It is in this specific context that the 
current findings support the promotion of multiple goals. Distance learners who learn with deep and regulatory strategies and consider the learning interesting and maintain a higher level of confidence are more likely to persist. It can be said that multiple goal learners are more motivated, though this may not necessarily lead to better results.

While this 'multiple pathways' argument may be sufficient to explain why multiple-goal learners (HH) and mastery-only learners (HL) had similar levels of achievement in their course assignments and examination, it does not help explain why learners in the LH and LL groups could also achieve similar scores in these assessment tasks to those in the HH and HL groups. One plausible explanation is that the LH and LL learners might have engaged in "periods of achievement spark" in order to deal with immediate demands for completing the written assignments and passing the examination. During such highly motivated periods, these learners might have engaged intensively and strategically in order to complete the required academic tasks. However, for most of the time during the academic year, they might be settled with a minimum level of motivation and engagement sufficient to get them through their courses. Another plausible explanation is that these two groups of learners might have relied on other forms of motivation to drive their learning. For example, $\mathrm{Ng}$ (2008) found that distance learners who held strong work-related goals had better performance than did those focusing on mastery and performance-approach goals, combined or separately. Certainly, additional research is required to look into the "achievement spark" hypothesis and explore distance learners' alternative motivation in addition to mastery and performance considerations.

The nonsignificant result between the HH and HL groups of distance learners in achievement levels prevents us from making a strong claim about endorsing multiple goals over the use of mastery goals. However, the current prospective study showed that multiple goals learners (HH) maintained a more engaged pattern of learning than did the mastery-only learners across three points of learning over an academic year. Given the challenge of sustaining engagement over the prolonged period of distance learning, endorsing multiple goals in one's goal profile should be optimal for distance learners. Of course, the current findings warn us that holding a multiple goal profile does not necessarily lead to a better achievement level. Further research on the effects of multiple goals on achievement among distance learners is still warranted. Finally, aligning with previous studies (e.g. Meece \& Holt, 1993), the current research and its findings highlighted the importance of a person-centred analytical lens to examine the effects of multiple goals on learning and achievement.

The current results need to be interpreted with the following considerations. This study did not assess learners' prior achievement levels, which is an important factor that should be examined or controlled for in the future research. Further, Barron and Harackiewicz (2001) located significant effects of multiple goals on achievement using a sample of students enrolled in a single course. The current study, however, involved distance learners in diverse courses and therefore variation in assignment and examination grading processes in different courses may be another important This work is licensed under a Creative Commons Attribution 4.0 International License 
factor that might have contributed to the nonsignificant difference in achievement levels between the four groups of goal users.

In conclusion, the current findings indicate that distance learners learn with different goal profiles that are associated with different learning patterns. An important finding in this study was that distance learners who endorsed both mastery and performance-approach goals engaged in deep learning using adaptive strategies consistently throughout an academic year. These multiple goal learners remained interested in learning and had confidence in their learning abilities across three different survey points over the year. This finding is consistent with previous research using distance learners (e.g. Ng, 2009) and campus-based students (e.g. Barron \& Harackiewicz, 2001). Given the associated engaged learning pattern, it is less likely for this type of motivated learners who persistently find learning interesting and remain confident about their abilities to drop out of their distance education courses and programs. While endorsing both goals may not necessarily lead to higher achievement levels, it is important to recognise that distance learners who learn with these goals are more engaged in their learning. Future research needs to examine how these goals can be promoted in distance education courses and programs in order that distance learners remain motivated and persist with their learning. 


\section{References}

Archer, J . (1994). Achievement goals as measure of motivation in university students. Contemporary Educational Psychology, 19, 430-446. doi:10.1006/ceps.1994.1031

Barron, K. E., \& Harackiewicz, J . M. (2001). Achievement goals and optimal motivation: Testing multiple goal models. J ournal of Educational Psychology, 80(5), 706-722. doi:10.1016/ B978-012619070-0/50031-3

Biggs, J . (1987). Student approaches to learning and studying. Melbourne: Australian Council for Educational Research.

Cannon, M. M., Umble, K. E., Steckler, A., \& Shay, S. (2001). "We're living what we're learning": Student perspectives in distance learning degree and certificate programs in public health. J ournal of Public Management Practice, 7(1), 49-59.

Cochrane, C. (2000). The reflections of a distance learner 1977-1997. Open Learning, 15(1), 17-34. doi:10.1080/026805100115443

Darnon, C., Dompnier, B., Gilliéron, O., \&Butera, F. (2010). The interplay of mastery and performance goals in social comparison: A multiple-goal perspective. J ournal of Educational Psychology, 102(1), 212-222. doi:10.1037/a0018161

Dearnley, C., \&Matthew, B. (2000). A group of nurses' experience open learning: Exploring the impact. Open Learning, 15(2), 191-206. doi:10.1080/ 713688397

Dweck, C. S. (1986). Motivational processes affecting learning. American Psychologist, 41(10), 1040-1048. doi:10.1037//0003-066X.41.10.1040

Elliot, M. A., \& Harackiewicz, J . (1996). Approach and avoidance achievement goals and intrinsic motivation: A mediational analysis. J ournal of Personality and Social Psychology, 70, 968-980. doi:10.1037// 0022-3514.70.3.461

Eppler, M. A., \&Harju, B. L. (1997). Achievement motivation goals in relation to academic performance in traditional and non-traditional college students. Research in Higher Education, 38, 557-573. doi:10.1023/ A:1024944429347

Harackiewicz, J . M., Barron, E., Carter, S. M., Lehto, A. T., \&Elliot, A. J . (1997). Predictors and consequences of achievement goals in the college classroom: Maintaining interest and making the grade. J ournal of Personality and Social Psychology, 73, 1284-1295.

doi:10.1037// 0022-3514.73.6.1284

This work is licensed under a Creative Commons Attribution 4.0 International License. 
Hulleman, C. S., Schrager, S. M., Bodmann, S. M., \& Harackiewicz, J . M. (2010). A meta-analytic review of achievement goal measures: Different labels for the same constructs or different constructs with similar labels? Psychological bulletin, 136(3), 422.

Liyanagunawardena, T. R., Adams, A. A., \&Williams, S. A. (2013). MOOCs: A systematic study of the published literature 2008-2012. International Review of Research in Open and Distance Learning, 14(3), 202-227.

Lyall, R., \& McNamara, S. (2000). Influences on the orientations to learning of distance education students in Australia. Open Learning, 15(2), 107-121. doi:10.1080/ 713688396

Meece, J . L., \& Holt, K. (1993). A pattern analysis of students' achievement goals. J ournal of Educational Psychology, 85(4), 582-590. doi:10.1037//0022-0663.85.4.582

Midgley, C., Kaplan, A., \& Middleton, M. (2001). Performance-approach goals: What, for whom, under what circumstances, and at what cost? J ournal of Educational Psychology, 93(1), 77-86. doi:10.1037// 0022-0663.93.1.77

Midgley, C., Maehr, M. L., Hruda, L. Z., Anderman, E., Anderman, L., Freeman, K. E., Gheen, M., Kaplan, A., Kumar, R., Middleton, M.J ., Nelson, J ., Roeser, R., \&Urdan, T. (2000). The patterns of adaptive learning scales. Ann Arbor: University of Michigan.

Miller, C., \& Smith, C. (1998). Professional development by distance education: Does distance lend enhancement? Cambridge Journal of Education, 28(2), 221-230. doi:10.1080/0305764980280207

Ng, C. H. (2006). The role of achievement goals in the completion of a course assignment: Examining the effects of performance-approach goals and combined goals. Open Learning, 21(1), 33-48. doi:10.1080/02680510500472189

Ng, C. H. (2008). Multiple-goal learners and their differential patterns of learning. Educational Psychology, 28(4), 439-456. doi:10.1080/01443410701739470

Ng, C. H. (2009). Profiling learners' achievement goals when completing academic essays. Educational Psychology, 29(3), 279-296. doi:10.1080/01443410902797988

Pintrich, P. R. (2000). Multiple goals, multiple pathways: The role of goal orientation in learning and achievement. J ournal of Educational Psychology, 92(3), 544-555. doi:10.1037// 0022-0663.92.3.544

Pintrich, P. R., Conley, A. M., \& Kempler, T. M. (2003). Current issues in achievement goal theory and research. International J ournal of Educational Research, 39, 319-337. doi:10.1016/j.jjer.2004.06.002 
Pintrich, P. R., Smith, D. A. F., \& Garcia, T. (1993). Reliability and predictive validity of the motivated strategies for learning questionnaire (MSLQ). Educational and Psychological Measurement, 53(3), 801-813. doi:10.1177/0013164493053003024

Remedios, R., \& Richardson, J . T. E. (2012). Achievement goals in adult learners: Evidence from distance education. British J ournal of Educational Psychology, 83(4), 664-685. doi:10.1111/bjep.12001

Sachs, J . (2001). A path model for adult learner feedback. Educational Psychologist, 21, 267-275. doi:10.1080/01443410123859

Senko, C., Hulleman, C. S., \& Harackiewicz, J . (2011). Achievement goal theory at the crossroads: Old controversies, current challenges, and new directions. Educational Psychologist, 46(1), 26-27. doi:10.1080/00461520.2011.538646

Simpson, O. (2008). Motivating learners in open and distance learning: do we need a new theory of learner support? Open Learning, 23(3), 159-170.

Simpson, O. (2013). Student retention in distance education: are we failing our students? Open Learning, 28(2), 105-119.

Skaalvik, E. M. (1997). Self-enhancing and self-defeating ego orientation: Relations with task and avoidance orientation, achievement, self-perception, and anxiety. J ournal of Educational Psychology, 89, 71-81. doi:10.1037/0022-0663.89.1.71

Valle, A., Cabanach, R. G., Núñez, J . C., González-Pienda, J ., Rodríguez, S., \& Piñeiro, I. (2003). Multiple goals, motivation and academic learning. British J ournal of Educational Psychology, 73, 71-87. doi:10.1348/000709903762869923

von Prummer, C. (1990). Study motivation of distance students: A report on some results from a survey done at the FernUniverstat in 1987/ 88. Research in Distance Education, 2(2), 2-6.

Wilson, V., \& Bagley, L. (1999). Learning at a distance: The case of the community pharmacist. International J ournal of Lifelong Education, 18(5), 355-369. doi:10.1080/026013799293603

Wolters, C. A. (2004). Advancing achievement goal theory: Using goal structures and goal orientations to predict students' motivation, cognition, and achievement. J ournal of Educational Psychology, 96(2), 236-250. doi:10.1037/ 0022-0663.96.2.236 
(C) $\mathrm{Ng}$

\section{Athabasca University $\mathbf{A}$}

(c) 